\title{
COVID-19 Awareness Among Healthcare Students and Professionals in Mumbai Metropolitan Region: A Questionnaire-Based Survey
}

Pranav D. Modi ${ }^{1}$, Girija Nair ${ }^{1}$, Abhay Uppe ${ }^{2}$, Janhavi Modi ${ }^{3}$, Balaji Tuppekar ${ }^{1}$, Amit S. Gharpure ${ }^{4}$, Deepak Langade ${ }^{5}$

1. Pulmonary Medicine, D Y Patil Hospital, Navi Mumbai, IND 2. Pulmonology, D Y Patil Hospital, Navi Mumbai, IND 3. Oral and Maxilofacial Surgery, Y.M.T. Dental College and Hospital, Navi Mumbai, IND 4. Periodontics, University of Washington School of Dentistry, Seattle, USA 5. Pharmacology, D Y Patil University - School of Medicine, Navi Mumbai, IND

Corresponding author: Pranav D. Modi, pranavdmodiresearch@gmail.com

\section{Abstract}

\section{Background and objectives}

The rapid and extensive spread of the COVID-19 pandemic has become a major cause of concern for the healthcare profession. The aim of this study is to assess the awareness of COVID-19 disease and related infection control practices among healthcare professionals and students in the Mumbai Metropolitan Region.

\section{Materials and methods}

A total of 1562 responders from the Mumbai Metropolitan Region completed a questionnaire-based survey on the awareness, knowledge, and infection control practices related to COVID-19 infection in the healthcare setting. The questionnaire was adapted from the current interim guidance and information for healthcare workers published by the US Centers for Disease Control and Prevention (CDC). Convenient sampling method was used for data collection and the distribution of responses was presented as frequencies and percentages. Descriptive statistics were performed for all groups and subgroups based on the percentage of correct responses. Individual pairwise comparisons were done using the median test for the percentage of correct responses.

\section{Results}

The overall awareness for all subgroups was adequate with $71.2 \%$ reporting correct answers. The highest percentage of correct responses were from undergraduate medical students and the lowest was from nonclinical/administrative staff. Less than half of the total respondents could correctly define "close contact." More than three-fourths of the responders were aware of the various infection control measures like rapid triage, respiratory hygiene, and cough etiquette and having a separate, well ventilated waiting area

Received 03/25/2020 Review began 03/28/2020 Review ended 03/29/2020 Published 04/02/2020

\section{() Copyright 2020}

Modi et al. This is an open access article distributed under the terms of the Creative Commons Attribution License CC-BY 4.0., which permits unrestricted use, distribution, and reproduction in any medium, provided the original author and source are credited. for suspected COVID-19 patients. However, only $45.4 \%$ of the responders were aware of the correct sequence for the application of a mask/respirator, and only $52.5 \%$ of the responders were aware of the preferred hand hygiene method for visibly soiled hands.

\section{Conclusion}

There is a need for regular educational interventions and training programs on infection control practices for COVID-19 across all healthcare professions. Occupational health and safety are of paramount importance to minimize the risk of transmission to healthcare students and professionals and provide optimal care for patients.

Categories: Medical Education, Infectious Disease, Epidemiology/Public Health

Keywords: covid-19 india, covid-19 mumbai, coronavirus, health care workers, who coronavirus, cdc coronavirus, covid-19, healthcare professionals, ppe, hand hygiene

\section{Introduction}

India braces for the COVID-19 pandemic; healthcare workers on the frontlines are particularly vulnerable to this infection. The virus that causes COVID - 19 was initially called as $2019-\mathrm{nCoV}$ and was then termed as syndrome coronavirus 2 (SARS-CoV-2) by the International Committee on Taxonomy of Viruses (ICTV) [1]. It is a new strain discovered in 2019 which was not found previously in humans.

Previously, the severe acute respiratory syndrome-coronavirus (SARS-CoV) and the Middle East respiratory syndrome-coronavirus (MERS-CoV) have been known to affect humans. Outbreaks of respiratory disease caused by these viruses seem to have originated in animals before moving into other hosts like humans. 
MERS-CoV was found to be transmitted from Arabian camels to humans, whereas SARS-CoV was transmitted from civet cats to humans. SARS-CoV-2 seems to have originated from bats and first reports of cases were from Wuhan, Hubei Province in China, suggesting an animal-to-person spread from a live animal market. The virus then spread outside Hubei and subsequently, to the rest of the world via human transmission. Several countries have now reported community spread. The World Health Organization (WHO) declared coronavirus disease as a pandemic on March 11, 2020 [2].

With this mode of transmission, healthcare workers are among the highest risk of being infected. The highly contagious SARS-CoV-2 virus is an additional hazard for the healthcare system apart from the burden of extended work hours, physical and psychological stress, burnout, and fatigue [3]. The objective of this study is to assess the awareness of COVID-19 disease and its related infection control practices among healthcare professionals in the Indian healthcare scenario. This was a questionnaire-based survey adapted from current interim guidelines and information for healthcare personnel provided by the US Centers for Disease Control and Prevention (CDC) and WHO.

\section{Materials And Methods}

This survey was conducted at a tertiary-care hospital and teaching institute in Navi Mumbai. The survey was prepared in the form of an online form and was sent to 4450 potential responders who included students and staff at various healthcare institutions in the Mumbai Metropolitan Region in the state of Maharashtra, India. The period of the survey was March 12-19, 2020, and a total of 1562 responders completed the survey with a response rate of $35.1 \%$.

The self-administered questionnaire consisting of socio-demographic questions, and 17 questions based on knowledge and infection control practices related to COVID-19 disease in the healthcare setting were adapted from the current interim guidance and information for healthcare workers published by the CDC, updated on March 7, 2020 [4]. The questionnaire also included questions related to hand hygiene techniques based on the "five moments of hand hygiene" described by the WHO, which were used to test participants' knowledge in optimal hygiene practices [5].

Consent was obtained by all participants in this study. The Institutional Ethics Committee (IEC) reviewed and approved the study-related documents (DYP/IECBH/2020/01). Convenient sampling method was used for data collection, and the distribution of responses was presented as frequency and percentages. Subgroups were classified on the basis of gender, age (18-30 years, 31-45 years, and >45 years) and profession (undergraduate, graduate students and faculty from medical, dental nursing, and physical therapy schools and institutes, non-clinical staff and administrators, paramedical staff, and professionals from the allied health sciences). Sub-groups were also classified on the basis of the training received by the responders for hand hygiene procedures. Data were tabulated in excel, and descriptive statistics were performed using SPSS 17. Individual pairwise comparisons were done using the median test for percent correct response.

\section{Results}

A total of 1562 healthcare professionals from the Mumbai Metropolitan Region responded to the survey. The majority of the responders were from the age group of $18-30$ years $(n=1136)$. Approximately $75.9 \%(n=$ $1,185)$ of the responders were females and $83.5 \%$ of the responders were from the city of Navi Mumbai. Among the various sub-groups, $33.1 \%(n=517)$ of the medical students, $24.3 \%(n=379)$ of the nursing staff and students and $10.9 \%(\mathrm{n}=171)$ of the medical postgraduates, fellows, and faculty completed the survey (Table 1). 


\section{Cureus}

\begin{tabular}{|c|c|c|c|}
\hline Demographic Group & Sub-Group & No. & $\%$ \\
\hline \multirow[t]{4}{*}{ Age group } & $18-30 \mathrm{yrs}$ & 1376 & 88.1 \\
\hline & $31-45$ yrs & 120 & 7.7 \\
\hline & $>45 \mathrm{yrs}$ & 66 & 4.2 \\
\hline & Total & 1562 & 100 \\
\hline \multirow[t]{3}{*}{ Gender } & Male & 377 & 24.1 \\
\hline & Female & 1185 & 75.9 \\
\hline & Total & 1562 & 100 \\
\hline \multirow[t]{4}{*}{ Location } & Mumbai: South \& Central & 91 & 5.8 \\
\hline & Mumbai: Western & 77 & 4.9 \\
\hline & Navi Mumbai & 1304 & 83.5 \\
\hline & Others & 90 & 5.8 \\
\hline Total & & 1562 & 100 \\
\hline \multirow[t]{8}{*}{ Profession } & Allied Health Sciences & 141 & 9 \\
\hline & Dentistry (students and faculty) & 142 & 9.1 \\
\hline & Medical Post-Graduates & 172 & 10.9 \\
\hline & Medical Students & 517 & 33.1 \\
\hline & Non-clinical/admin staff & 12 & 8 \\
\hline & Nursing (students and faculty) & 379 & 24.3 \\
\hline & Paramedical staff & 37 & 2.4 \\
\hline & Physiotherapy/Occupational therapy (students and faculty) & 163 & 10.4 \\
\hline Total & & 1562 & 100 \\
\hline
\end{tabular}

TABLE 1: Responder profile

The responses of various professional sub-groups, gender, and age have been presented in Tables 2 and 3 . 


\section{Cureus}

\begin{tabular}{|c|c|c|c|c|c|c|c|c|c|c|c|c|}
\hline & \multicolumn{6}{|l|}{ Age } & \multicolumn{4}{|c|}{ Gender } & & \\
\hline & \multicolumn{2}{|c|}{$\begin{array}{l}18 \text { to } 30 \text { years }(n= \\
1376)\end{array}$} & \multicolumn{2}{|c|}{$\begin{array}{l}31 \text { to } 44 \text { years }(n= \\
120)\end{array}$} & \multicolumn{2}{|c|}{$\begin{array}{l}45 \text { and above }(\mathrm{n} \\
=66)\end{array}$} & \multicolumn{2}{|c|}{$\begin{array}{l}\text { Female }(n= \\
1185)\end{array}$} & \multicolumn{2}{|c|}{$\begin{array}{l}\text { Male }(\mathrm{n}= \\
377)\end{array}$} & \multicolumn{2}{|c|}{$\begin{array}{l}\text { lotal }(n= \\
1562)\end{array}$} \\
\hline & No. & $\%$ & No. & $\%$ & No. & $\%$ & No. & $\%$ & No. & $\%$ & No. & $\%$ \\
\hline Q-1 & 185 & $13.4 \%$ & 7 & $5.8 \%$ & 6 & $9.1 \%$ & 151 & $12.7 \%$ & 47 & $12.5 \%$ & 198 & $12.68 \%$ \\
\hline Q-2 & 1361 & $98.9 \%$ & 120 & $100.0 \%$ & 63 & $95.5 \%$ & 1170 & $98.7 \%$ & 374 & $99.2 \%$ & 1544 & $98.85 \%$ \\
\hline Q-3 & 872 & $63.4 \%$ & 70 & $58.3 \%$ & 27 & $40.9 \%$ & 738 & $62.3 \%$ & 231 & $61.3 \%$ & 969 & $62.04 \%$ \\
\hline Q-4 & 608 & $44.2 \%$ & 53 & $44.2 \%$ & 31 & $47.0 \%$ & 512 & $43.2 \%$ & 180 & $47.7 \%$ & 692 & $44.30 \%$ \\
\hline Q-5 & 1200 & $87.2 \%$ & 102 & $85.0 \%$ & 58 & $87.9 \%$ & 1033 & $87.2 \%$ & 327 & $86.7 \%$ & 1360 & $87.07 \%$ \\
\hline $\begin{array}{l}\text { Q-6 Yes - Received Prior Hand Hygiene } \\
\text { Training }\end{array}$ & 209 & $15.2 \%$ & 21 & $17.5 \%$ & 28 & $42.4 \%$ & 202 & $17.0 \%$ & 56 & $14.9 \%$ & & \\
\hline $\begin{array}{l}\text { Q-6 No - Not Received Prior Hand } \\
\text { Hygiene Training }\end{array}$ & 1167 & $84.8 \%$ & 99 & $82.5 \%$ & 38 & $57.6 \%$ & 983 & $83.0 \%$ & 321 & $85.1 \%$ & & \\
\hline Q-7 & 1211 & $88.0 \%$ & 107 & $89.2 \%$ & 55 & $83.3 \%$ & 1048 & $88.4 \%$ & 325 & $86.2 \%$ & 1373 & $87.90 \%$ \\
\hline Q-8 & 854 & $62.1 \%$ & 87 & $72.5 \%$ & 44 & $66.7 \%$ & 757 & $63.9 \%$ & 228 & $60.5 \%$ & 985 & $63.06 \%$ \\
\hline Q-9 & 1072 & $77.9 \%$ & 102 & $85.0 \%$ & 52 & $78.8 \%$ & 924 & $78.0 \%$ & 302 & $80.1 \%$ & 1226 & $78.49 \%$ \\
\hline Q-10 & 1247 & $90.6 \%$ & 115 & $95.8 \%$ & 65 & $98.5 \%$ & 1074 & $90.6 \%$ & 353 & $93.6 \%$ & 1427 & $91.36 \%$ \\
\hline Q-11 & 1197 & $87.0 \%$ & 111 & $92.5 \%$ & 64 & $97.0 \%$ & 1033 & $87.2 \%$ & 339 & $89.9 \%$ & 1372 & $87.84 \%$ \\
\hline Q-12 & 1092 & $79.4 \%$ & 91 & $75.8 \%$ & 51 & $77.3 \%$ & 930 & $78.5 \%$ & 304 & $80.6 \%$ & 1234 & $79.00 \%$ \\
\hline Q-13 & 751 & $54.6 \%$ & 67 & $55.8 \%$ & 34 & $51.5 \%$ & 630 & $53.2 \%$ & 222 & $58.9 \%$ & 852 & $54.55 \%$ \\
\hline Q-14 & 566 & $41.1 \%$ & 46 & $38.3 \%$ & 19 & $28.8 \%$ & 467 & $39.4 \%$ & 164 & $43.5 \%$ & 631 & $40.40 \%$ \\
\hline Q-15 & 1027 & $74.6 \%$ & 100 & $83.3 \%$ & 55 & $83.3 \%$ & 892 & $75.3 \%$ & 290 & $76.9 \%$ & 1182 & $75.67 \%$ \\
\hline Q-16 & 1240 & $90.1 \%$ & 112 & $93.3 \%$ & 59 & $89.4 \%$ & 1057 & $89.2 \%$ & 354 & $93.9 \%$ & 1411 & $90.33 \%$ \\
\hline Q-17 & 1204 & $87.5 \%$ & 100 & $83.3 \%$ & 54 & $81.8 \%$ & 1026 & $86.6 \%$ & 332 & $88.1 \%$ & 1358 & $86.94 \%$ \\
\hline Overall correct percentage (Median) & & $71.2 \%$ & & $72.4 \%$ & & $69.8 \%$ & & $74.8 \%$ & & $72.5 \%$ & & $71.3 \%$ \\
\hline
\end{tabular}

TABLE 2: Percentage of correct responses in different age groups and gender 


\begin{tabular}{|c|c|c|c|c|c|c|c|c|c|c|c|c|c|c|c|c|}
\hline & \multicolumn{16}{|c|}{ Profession } \\
\hline & \multicolumn{2}{|c|}{$\begin{array}{l}\text { Allied health } \\
\text { sciences }(n= \\
141)\end{array}$} & \multicolumn{2}{|c|}{$\begin{array}{l}\text { Dentistry } \\
\text { (Students and } \\
\text { faculty) }(n=142)\end{array}$} & \multicolumn{2}{|c|}{$\begin{array}{l}\text { Medical Post-graduates } \\
\text { (residents, fellows, faculty) } \\
(n=171)\end{array}$} & \multicolumn{2}{|c|}{$\begin{array}{l}\text { Medical } \\
\text { Students }(\mathrm{n}= \\
517)\end{array}$} & \multicolumn{2}{|c|}{$\begin{array}{l}\text { Non- } \\
\text { clinical/administrative } \\
\text { staff }(n=12)\end{array}$} & \multicolumn{2}{|c|}{$\begin{array}{l}\text { Nursing } \\
\text { (Students \& } \\
\text { faculty) }(n= \\
379)\end{array}$} & \multicolumn{2}{|c|}{$\begin{array}{l}\text { Paramedical } \\
\text { staff }(n=37)\end{array}$} & \multicolumn{2}{|c|}{$\begin{array}{l}\text { Physiotherapy, } \\
\text { occupational therapy } \\
\text { (students and faculty) (n= } \\
\text { 163) }\end{array}$} \\
\hline & $\mathrm{N}$ & $\%$ & $\mathrm{~N}$ & $\%$ & $\mathrm{~N}$ & $\%$ & $\mathrm{~N}$ & $\%$ & $\mathrm{~N}$ & $\%$ & $\mathrm{~N}$ & $\%$ & $\mathrm{~N}$ & $\%$ & $\mathrm{~N}$ & $\%$ \\
\hline Q-1 & 20 & $14.2 \%$ & 7 & $4.9 \%$ & 9 & $5.3 \%$ & 55 & $10.6 \%$ & 2 & $16.7 \%$ & 69 & $18.2 \%$ & 12 & $32.4 \%$ & 24 & $14.7 \%$ \\
\hline Q-2 & 136 & $96.5 \%$ & 142 & $100.0 \%$ & 168 & $98.2 \%$ & 515 & $99.6 \%$ & 10 & $83.3 \%$ & 374 & $98.7 \%$ & 36 & $97.3 \%$ & 163 & $100.0 \%$ \\
\hline Q-3 & 81 & $57.4 \%$ & 77 & $54.2 \%$ & 97 & $56.7 \%$ & 363 & $70.2 \%$ & 2 & $16.7 \%$ & 229 & $60.4 \%$ & 28 & $75.7 \%$ & 92 & $56.4 \%$ \\
\hline Q-4 & 54 & $38.3 \%$ & 65 & $45.8 \%$ & 92 & $53.8 \%$ & 253 & $48.9 \%$ & 2 & $16.7 \%$ & 140 & $36.9 \%$ & 14 & $37.8 \%$ & 72 & $44.2 \%$ \\
\hline Q-5 & 120 & $85.1 \%$ & 135 & $95.1 \%$ & 151 & $88.3 \%$ & 474 & $91.7 \%$ & 8 & $66.7 \%$ & 294 & $77.6 \%$ & 26 & $70.3 \%$ & 152 & $93.3 \%$ \\
\hline $\begin{array}{l}\text { Q-6 Yes - Received } \\
\text { prior hand hygiene } \\
\text { training }\end{array}$ & 28 & $19.9 \%$ & 39 & $27.5 \%$ & 33 & $19.3 \%$ & 78 & $15.1 \%$ & 4 & $33.3 \%$ & 15 & $4.0 \%$ & 0 & $0.0 \%$ & 61 & $37.4 \%$ \\
\hline $\begin{array}{l}\text { Q-6 No - Did not } \\
\text { receive prior hand } \\
\text { hygiene training }\end{array}$ & 113 & $80.1 \%$ & 103 & $72.5 \%$ & 138 & $80.7 \%$ & 439 & $84.9 \%$ & 8 & $66.7 \%$ & 364 & $96.0 \%$ & 37 & $100.0 \%$ & 102 & $62.6 \%$ \\
\hline Q-7 & 116 & $82.3 \%$ & 121 & $85.2 \%$ & 155 & $90.6 \%$ & 466 & $90.1 \%$ & 9 & $75.0 \%$ & 336 & $88.7 \%$ & 32 & $86.5 \%$ & 138 & $84.7 \%$ \\
\hline Q-8 & 60 & $42.6 \%$ & 108 & $76.1 \%$ & 113 & $66.1 \%$ & 361 & $69.8 \%$ & 4 & $33.3 \%$ & 200 & $52.8 \%$ & 27 & $73.0 \%$ & 112 & $68.7 \%$ \\
\hline Q-9 & 96 & $68.1 \%$ & 130 & $91.5 \%$ & 153 & $89.5 \%$ & 429 & $83.0 \%$ & 7 & $58.3 \%$ & 251 & $66.2 \%$ & 26 & $70.3 \%$ & 134 & $82.2 \%$ \\
\hline Q-10 & 111 & $78.7 \%$ & 136 & $95.8 \%$ & 169 & $98.8 \%$ & 494 & $95.6 \%$ & 9 & $75.0 \%$ & 320 & $84.4 \%$ & 33 & $89.2 \%$ & 155 & $95.1 \%$ \\
\hline Q-11 & 128 & $90.8 \%$ & 129 & $90.8 \%$ & 163 & $95.3 \%$ & 449 & $86.8 \%$ & 9 & $75.0 \%$ & 327 & $86.3 \%$ & 30 & $81.1 \%$ & 137 & $84.0 \%$ \\
\hline Q-12 & 114 & $80.9 \%$ & 129 & $90.8 \%$ & 121 & $70.8 \%$ & 403 & $77.9 \%$ & 9 & $75.0 \%$ & 291 & $76.8 \%$ & 27 & $73.0 \%$ & 140 & $85.9 \%$ \\
\hline Q-13 & 70 & $49.6 \%$ & 86 & $60.6 \%$ & 78 & $45.6 \%$ & 301 & $58.2 \%$ & 7 & $58.3 \%$ & 200 & $52.8 \%$ & 12 & $32.4 \%$ & 98 & $60.1 \%$ \\
\hline Q-14 & 58 & $41.1 \%$ & 50 & $35.2 \%$ & 65 & $38.0 \%$ & 218 & $42.2 \%$ & 2 & $16.7 \%$ & 163 & $43.0 \%$ & 12 & $32.4 \%$ & 63 & $38.7 \%$ \\
\hline Q-15 & 96 & $68.1 \%$ & 121 & $85.2 \%$ & 141 & $82.5 \%$ & 415 & $80.3 \%$ & 3 & $25.0 \%$ & 246 & $64.9 \%$ & 25 & $67.6 \%$ & 135 & $82.8 \%$ \\
\hline Q-16 & 121 & $85.8 \%$ & 133 & $93.7 \%$ & 164 & $95.9 \%$ & 490 & $94.8 \%$ & 10 & $83.3 \%$ & 314 & $82.8 \%$ & 29 & $78.4 \%$ & 150 & $92.0 \%$ \\
\hline Q-17 & 125 & $88.7 \%$ & 112 & $78.9 \%$ & 135 & $78.9 \%$ & 450 & $87.0 \%$ & 10 & $83.3 \%$ & 347 & $91.6 \%$ & 36 & $97.3 \%$ & 143 & $87.7 \%$ \\
\hline $\begin{array}{l}\text { Overall correct } \\
\text { percentage (Median) }\end{array}$ & & $66.7 \%$ & & $73.9 \%$ & & $72.1 \%$ & & $74.1 \%$ & & $53.6 \%$ & & $67.6 \%$ & & $68.4 \%$ & & $73.1 \%$ \\
\hline
\end{tabular}

TABLE 3: Distribution of correct responses according to profession

Only $22.6 \%$ of the responders were aware that the virus causing COVID-19 was initially called as 2019-nCoV and was later termed as syndrome coronavirus 2 (SARS-CoV-2). The main mode of transmission of the virus is via respiratory droplets which were answered correctly by $62 \%$ of the responders, with the lowest percentage of correct answers coming from the non-clinical/administrative staff sub-group (16.7\%).

Only $48.9 \%(n=692)$ of the total respondents were able to correctly define "close contact". The highest number of correct responses were from the medical undergraduate student sub-group (48.9\%; $n=253)$, and the lowest number was from the non-clinical/administrative staff sub-group (16.7\%). A majority (87.1\%) of the responders were able to correctly answer questions related to COVID-19 exposure that required medical attention.

Approximately $83 \%$ of the responders had received formal hand hygiene treatment in the last three years and $87.9 \%$ were aware of the moments of hand hygiene. However, only $52.5 \%$ of the responders were aware of the preferred hand hygiene method for visibly soiled hands. Interestingly, a higher number of correct responses were from the group which did not receive any formal hand hygiene training (Figure 1). 


\section{Cureus}

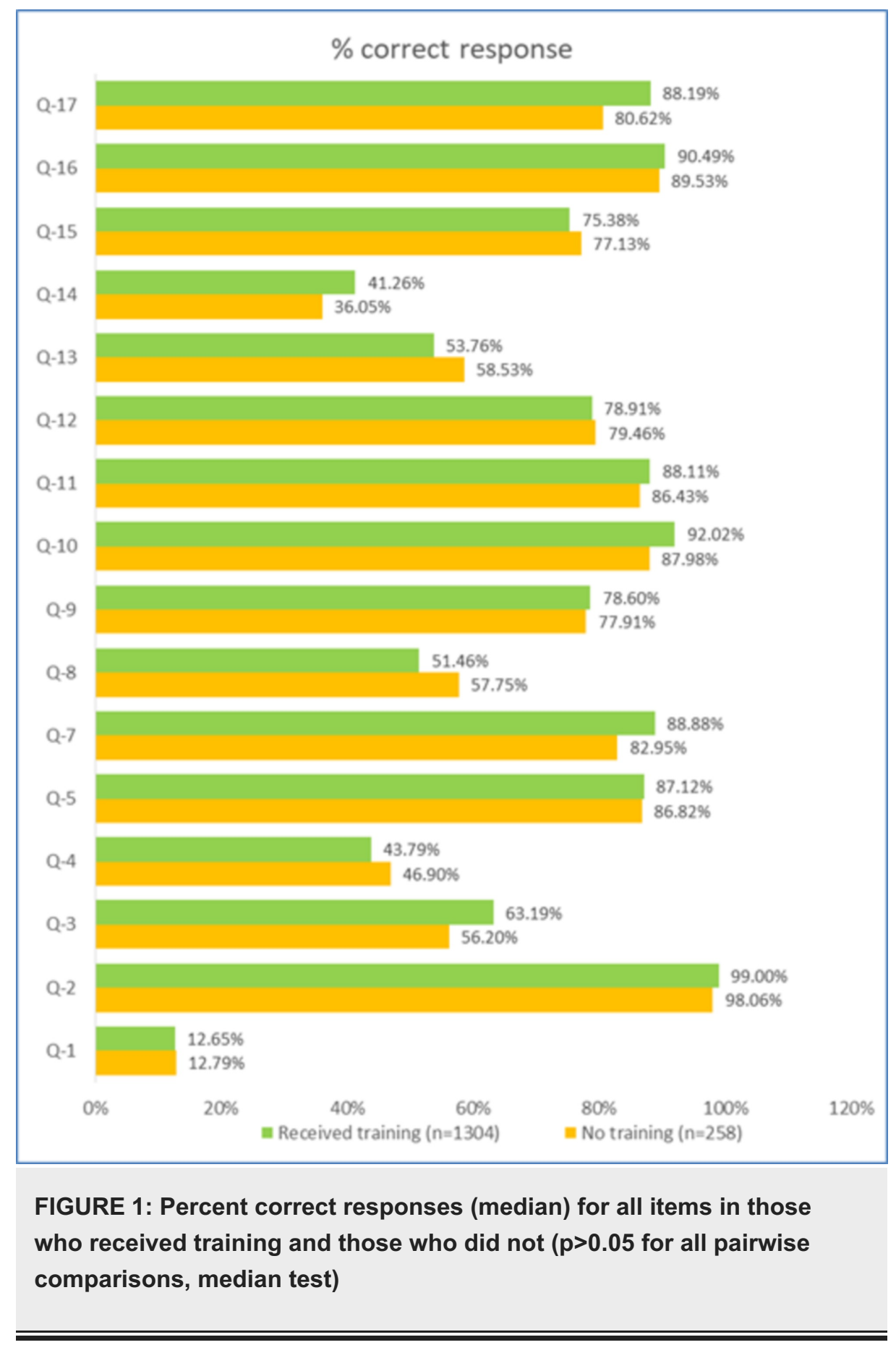

Seventy-nine percent of the responders were aware of the various personal protective equipment (PPE) recommended for use in suspected COVID-19 patients in a healthcare setting. Eighty-seven percent were aware of the essential PPE needed for transporting a suspected patient within a healthcare facility. Only $54.5 \%$ of the responders were aware of the isolation procedures necessary for a confirmed COVID-19 patient (Airborne Infection Isolation Room without exhaust). Out of the various sub-groups, the physiotherapy and occupational therapy group had the highest number of correct responses $(60.1 \%)$, whereas the lowest number was from paramedical staff sub-group (32.4\%). Eighty-seven percent of the responders were aware of the recommended infection prevention and control measures to perform aerosol-generating procedures.

Only $45.4 \%$ of the responders were aware of the right sequence for the application of a mask/respirator. The highest number of correct responses were from the nursing sub-group (43\%) and undergraduate medical student sub-group (42.2\%), whereas the lowest number was from the paramedical staff (32.4\%) and nonclinical/administrative staff (16.7\%) sub-groups.

More than $75 \%$ of the responders were aware of the various infection control measures like rapid triage, respiratory hygiene, and cough etiquette and having a separate, well-ventilated waiting area for suspected COVID-19 patients. 


\section{Cureus}

The overall percentage of correct answers for all groups was $71.2 \%$. A slightly higher percentage of correct responses were from the age sub-group of 18-30 (72.38\%) and from females (74.78\%). A higher percentage of correct answers were obtained from medical students, dentists, physiotherapy and occupational therapy group sub-groups (Figures 2-4).

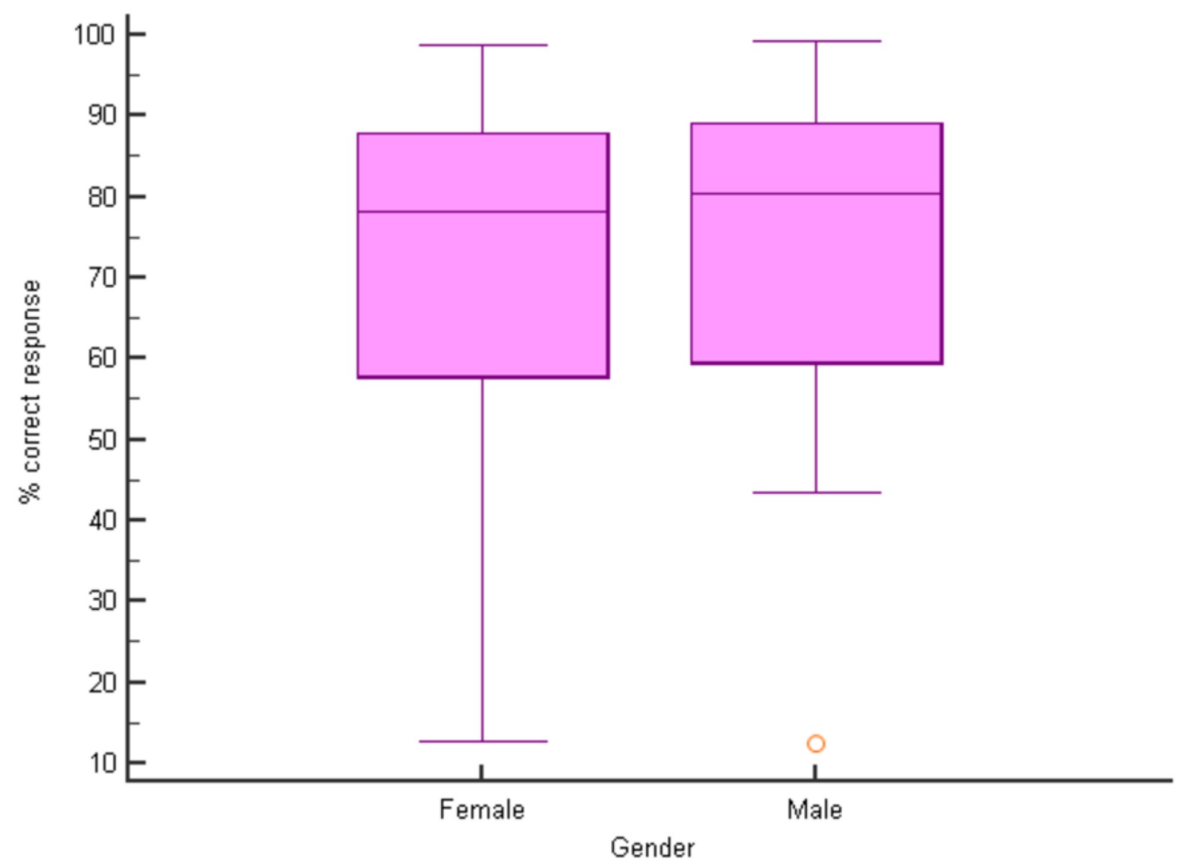

FIGURE 2: Percent correct responses (median) for males and females ( $p$ $>0.05$ for all pairwise comparisons, median test)

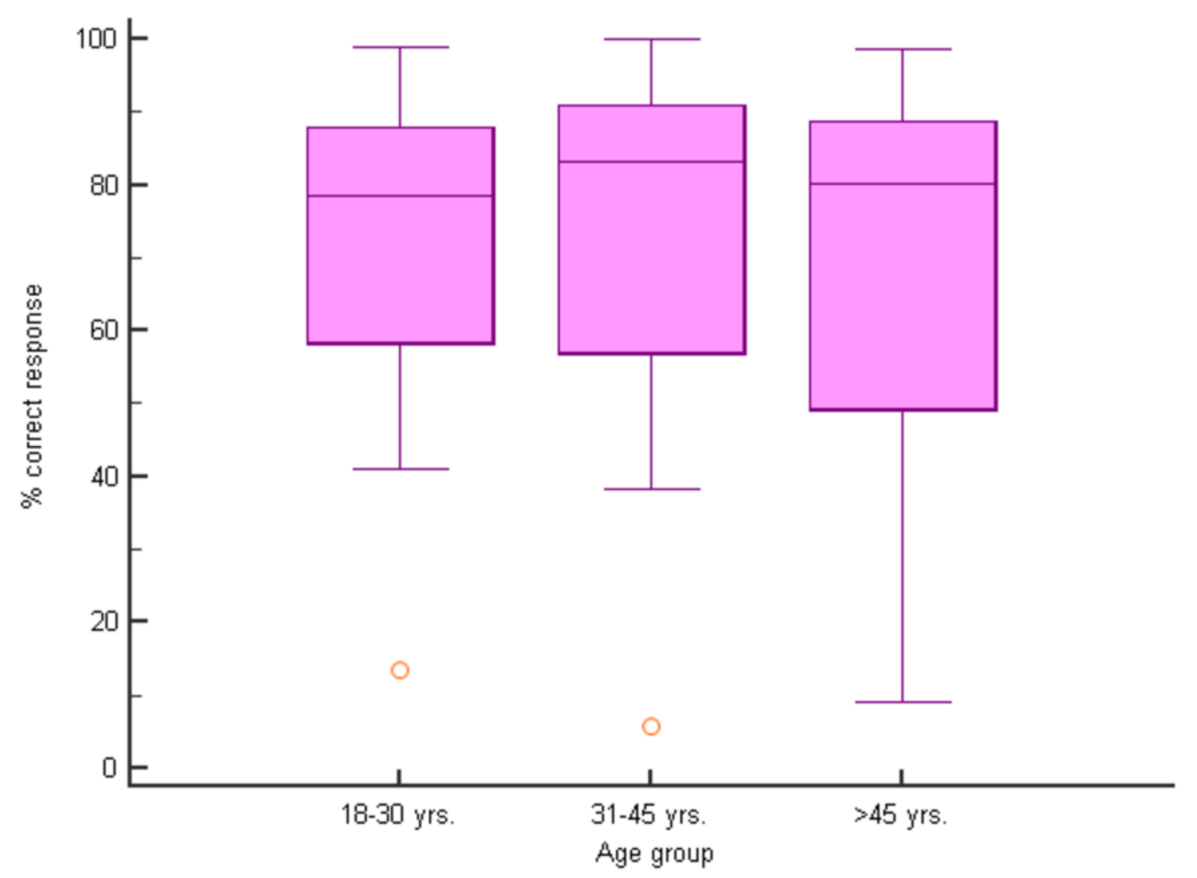

FIGURE 3: Percent correct responses (median) for different age groups ( $p>0.05$ for all pairwise comparisons, median test) 


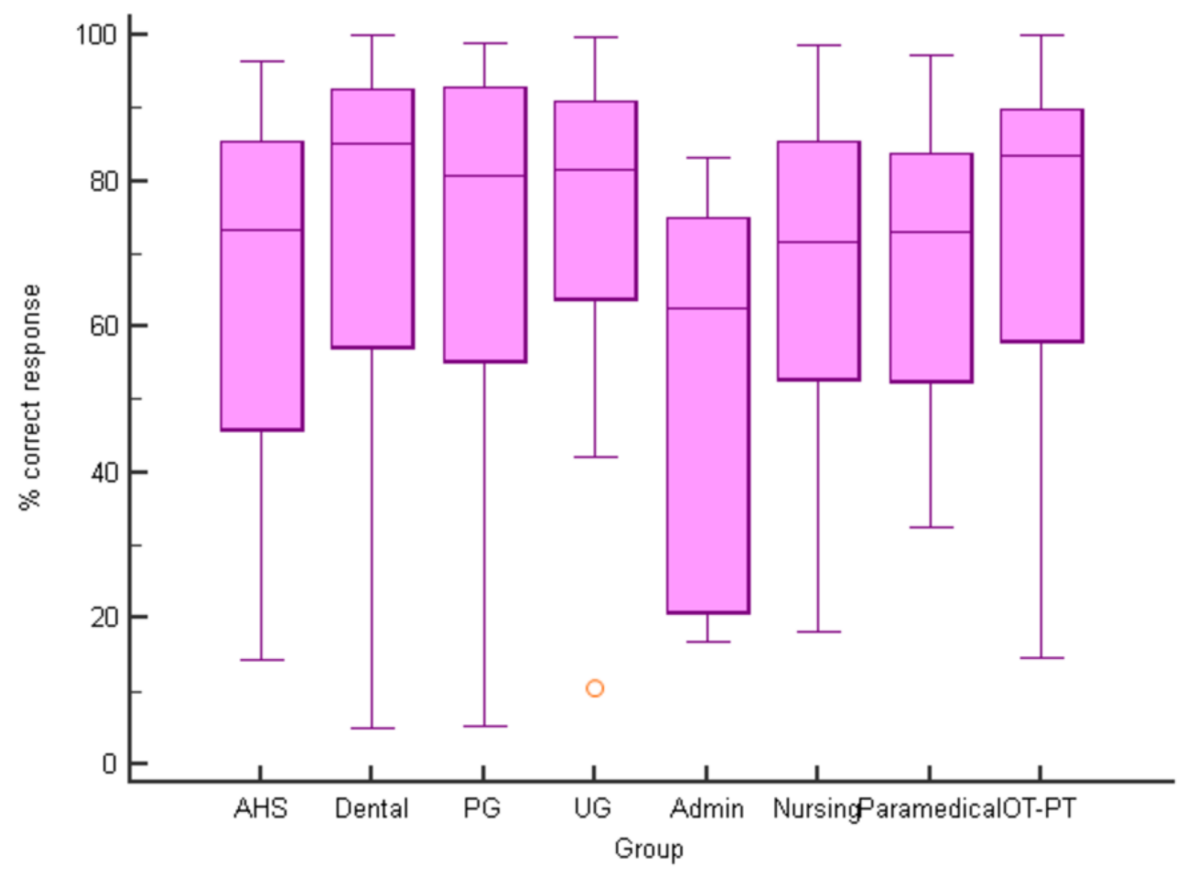

FIGURE 4: Percent correct responses (median) for different responders ( $p>0.05$ for all pairwise comparisons, median test)

AHS, Allied Health Sciences; UG, Undergraduate Medical Students; PG, Post-graduate Medical Students; OTPT, Occupational and Physical Therapy Students

\section{Discussion}

Since its initial outbreak in China in December 2019, the COVID-19 disease has had a cascading effect worldwide. According to the ICMR update on March 23, 2020, more than 400 individuals have been confirmed positive in India [6]. The identification and isolation of a suspected case is the most important step in curbing the spread of COVID-19. However, in our study, less than half of the responders were aware of defining a "close contact." According to the US CDC, a "close contact" is defined as: "being within approximately 6 feet (2 meters) of a COVID-19 case for a prolonged period of time or having direct contact with infectious secretions of a COVID-19 case. Similarly, various other key definitions have been provided in Interim U.S. Guidance for Risk Assessment and Public Health Management of Healthcare Personnel with Potential Exposure in a Healthcare Setting to Patients with Coronavirus Disease (COVID-19) published by the CDC [4]. Awareness was low among all subgroups with the lowest being the non-clinical/administrative staff. Even though this group is not actively involved in patient management, there are high chances of nonclinical staff having patient contact at some point in the healthcare setting and therefore at risk of contracting and spreading the infection.

Correct hand hygiene practices play a crucial role in preventing the spread of infection. The WHO "Five Moments of hand hygiene" defines key moments when healthcare providers must carry out hand hygiene [7]. Two basic methods to clean hands are hand washing and hand rubbing. The CDC recommends alcoholbased hand rub (ABHR) in most situations [8]. However, the question in our survey was focussed on the recommended hand hygiene technique for visibly soiled hands which is handwashing with soap and water for at least 20 seconds with the whole process lasting for up to 40-60 seconds [5].

Awareness of the use of personal protective equipment (PPE) for suspected/confirmed COVID-19 cases was high among all groups of healthcare professionals. The CDC has provided Interim Infection Prevention and Control Recommendations for Patients with suspected or confirmed coronavirus disease 2019 (COVID-19) in Healthcare Settings for PPE [9]. A Facemask/N95 respirator should be used when entering into the patient room. The N95 respirator is preferred over face mask when performing or presents for aerosol-generating procedures. Proper disposal of the used masks and hand hygiene should be performed. A clean gown with goggles or disposable face shield and clean non- sterile gloves are recommended upon entry to the patient room area. In case of shortage, gowns should be prioritized for aerosol-generating procedures.

Besides being aware of the required PPE, it is also important to know the correct sequence of "donning and doffing" of PPE. The CDC sequence of donning a face mask is as follows: securing ties or elastic bands at the middle of head and neck, fitting the flexible band to the nose bridge, fit snug to face and below the chin, fit- 


\section{Cureus}

check respirator [10] (Figure 5).

\section{SEQUENCE FOR PUTTING ON PERSONAL PROTECTIVE EQUIPMENT (PPE)}

The type of PPE used will vary based on the level of precautions required, such as standard and contact, droplet or airborne infection isolation precautions. The procedure for putting on and removing PPE should be tailored to the specific type of PPE.

\section{GOWN}

- Fully cover torso from neck to knees, arms to end of wrists, and wrap around the back

- Fasten in back of neck and waist

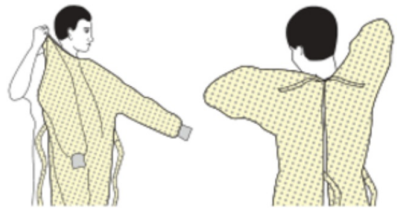

\section{MASK OR RESPIRATOR}

- Secure ties or elastic bands at middle of head and neck

- Fit flexible band to nose bridge

- Fit snug to face and below chin

- Fit-check respirator

\section{GOGGLES OR FACE SHIELD}

- Place over face and eyes and adjust to fit

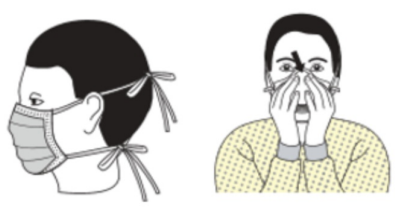

\section{GLOVES}

- Extend to cover wrist of isolation gown

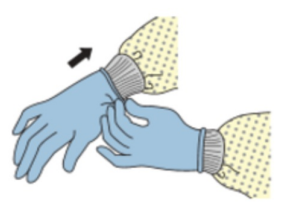

\section{USE SAFE WORK PRACTICESTO PROTECT YOURSELF AND LIMIT THE SPREAD OF CONTAMINATION}

- Keep hands away from face

- Limit surfaces touched

- Change gloves when torn or heavily contaminated

- Perform hand hygiene

\section{FIGURE 5: Sequence for putting on PPE}

This material was developed by The Centers for Disease Control and Prevention (https://www.cdc.gov/hai/pdfs/ppe/ppe-sequence.pdf)

PPE, personal protective equipment

More than $75 \%$ of the respondents were of the opinion that the use of a facemask/respirator is not essential or recommended for people who are well and not in contact with a suspected or infected COVID-19 patient. The general recommendation from all major global health organizations is that those in healthcare settings or those who are symptomatic should use a mask. Even though discrepancies have been observed for use in the community setting, the widespread use of masks should be discouraged to preserve limited supplies for healthcare settings [11].

Patient isolation and aerosol performing procedures should be carried out in the Airborne Infection Isolation Room (AIIR). These are rooms kept under negative pressure. Suspected or confirmed patients should not be placed in a room that has an exhaust that recirculates air within the hospital building. Air from these rooms should be filtered through a high-efficiency particulate air (HEPA) filter directly before recirculation. Less than half the responders in our survey were aware of this concept. 
The overall percentage of correct answers for our study participants was $71.2 \%$ with the highest percentage of correct responses from medical undergraduate students (74.10\%) and lowest from the non-

clinical/administrative staff (53.64\%). A cross-sectional study regarding knowledge and attitudes towards Middle East respiratory syndrome-coronavirus (MERS-CoV) was conducted on healthcare workers in primary healthcare centers and hospitals at Najran in Saudi Arabia which showed a majority of the healthcare workers were aware of MERS-CoV and had sufficient knowledge regarding the same. Physicians and nurses had significantly better knowledge compared with other healthcare workers [12]. The results of a similar survey carried out in healthcare workers in the Kingdom of Saudi Arabia suggested poor knowledge about emerging infectious diseases among study participants, and self-reported infection control practices were found to be sub-optimal. In South Korea, a survey study of healthcare workers suggested a poor level of knowledge of the modes of transmission of MERS coronavirus [13].

To the best of our knowledge, this is the first study that evaluates the awareness of COVID-19 among Indian healthcare students and professionals. In the midst of this crisis, the Indian health ministry has proposed to provisionally permit medical undergraduates of senior grades to treat COVID-19 patients [14]. This move could help plug the shortage of healthcare professionals and potentially provide care to a large number of people. Hence, students from various healthcare professions were included in our study.

The current situation demands urgent development of strategies to prevent infection among high-risk populations including pre-exposure and post-exposure prophylaxis. Various drugs including antivirals and antimalarials are under trial currently. In vitro drug testing has shown the antimalarial hydroxychloroquine to have antiviral activity against SARS-CoV-2 and could be potentially used as chemoprophylaxis for healthcare workers. Clinical trials for the treatment of COVID-19 pneumonia with hydroxychloroquine are underway and results of the same will be monitored closely in the coming days [15].

One of the drawbacks of this study is that most respondents are from urban locations in the Mumbai Metropolitan Region which do not truly represent the healthcare professionals of the entire state and country.

\section{Conclusions}

Healthcare professionals and students from the Mumbai Metropolitan Region showed adequate awareness of COVID-19 in the healthcare setting with an overall percentage of $71.2 \%$ correct answers. A higher percentage of correct responses were from undergraduate medical students and the lowest was from nonclinical/administrative staff. This study shows that there is a strong need to implement periodic educational interventions and training programs on infection control practices for COVID-19 across all healthcare professions. Conducting periodic webinars for educational intervention for all healthcare students and professionals including non-clinical and administrative staff, paramedical and nursing sub-groups could be a useful and safe tool to create more awareness.

Disclaimer: This article was last updated on March 23, 2020, and it may not be updated regularly. COVID-19 is an emerging, rapidly evolving situation and we recommend healthcare students and professionals to review the latest official information from local governments and health organizations.

\section{Appendices}




\section{Cureus}

\section{COVID-19 (Coronavirus Disease 2019) Awareness Among Healthcare Professionals in Mumbai Metropolitan Region}

Department Of Pulmonary Medicine, Dr. D. Y. Patil Hospital, Navi Mumbai

1) The virus causing COVID-19 infection is called
(A) Severe Acute Respiratory Syndrome Coronavirus (SARS)
(B) Severe Acute Respiratory Syndrome Coronavirus - 2 (SARS-CoV-2)
(C) 2019-nCoV
(D) Both $B$ and $C$
(E) Both $A$ and $C$

Ans: D

2) First reports of cases were from Wuhan city in the Hubei Province of China. True or False

Ans: True

3) The Main mode of transmission of virus from person to person is via: (A) Respiratory droplets

(B) Spread from contact with contaminated surfaces or objects

Ans: $A$

4) Which of the following is considered as "close contact" ? (A)Being within approximately 10 feet (3meters) of a patient with COVID-19 for a prolonged period of time

(B) being within approximately 6 feet ( 2 meters) of a patient with COVID-19 for a prolonged period of time.

(C) Having direct contact with infectious secretions (sputum, serum, blood) from a patient with COVID-19

(D) Both: options (B) and (C)

(E) Both: options $(A)$ and $(C)$

Ans: D

FIGURE 6: Questionnaire page 1 


\section{Cureus}

5) Reported illnesses have ranged from mild to severe symptoms of cough, fever, breathlessness which can appear 2-14 days after exposure. For which of the following situations is medical advice indicated?

(A)Have been in close contact with a person known to have COVID-19

(B)Currently residing in an area with ongoing COVID -19 infection

(C)Recent travel from an area with ongoing spread of COVID-19

(D) All of the above

Ans: D

6) Did you receive formal training in hand hygiene in the last three years? As applicable (Yes/No)

7) Which of the following hand hygiene actions prevents transmission of the virus to the health-care worker?

(A) After touching a patient

(B) Immediately after exposure to body fluids

(C) After exposure to immediate surroundings of the patient

(D) Before putting on and upon removal of personal protective equipment (PPE),

including gloves.

(E) All of the above

Ans: $\mathrm{E}$

8) Preferred method of hand hygiene for visibly soiled hands is:

(A) Hand rub with soap and water for at least 10 seconds

(B) Hand rub with soap and water for at least 20 seconds

(C) Use of alcohol based hand sanitizer with at least $60 \%$ alcohol

Ans: B

9) Use of a face mask is not essential in which of the following groups ?

(A) People who are well, to protect themselves from COVID-19 infection

(B) Being in close contact of a person suspected of or known to have COVID -19 infection

(C) Healthcare professionals

Ans: A

FIGURE 7: Questionnaire page 2 


\section{Cureus}

10) Which of the following is the most effective method for prevention of COVID -19 infection in the healthcare setting?

(A) Avoid exposure (Use Standard Precautions, Contact Precautions, and Airborne Precautions and eye protection when caring for patients with confirmed or possible COVID-19)

(B) Vaccination

Ans: A

(11) What personal protective equipment (PPE) should be worn by individuals transporting patients who are confirmed with or under investigation for COVID-19 within a healthcare facility?
(A)Gloves
(B)Gown
(C)Eye protection
(D)Respirator - N95 mask
(E) All of the above

Ans: $\mathrm{E}$

(12) What PPE should be worn by HCP providing care to asymptomatic patients with a history of exposure to COVID-19 who are being evaluated for a non-infectious complaint (e.g., hypertension or hyperglycemia)?
(A)Gloves
(B)Gown
(C)Eye protection
(D)Respirator - N95 mask
(E) All of the above

Ans: $E$

(13) Which of the following is recommended for isolation of a patient with confirmed COVID-19 and those under investigation for COVID-19?

(A) Airborne Infection Isolation Room (AllR) with exhaust

(B) Airborne Infection Isolation Room (AllR) without exhaust

Ans: $B$

FIGURE 8: Questionnaire page 3 
(B) Fit flexible band to nose bridge-> Secure ties or elastic bands at middle of head and neck-> Fit snug to face and below chin -> Fit-check respirator

Ans: A

(15) Which of the following are recommended infection control measures upon arrival of a patient with suspected COVID-19 infection?

(A)Rapid triage of symptomatic patients

(B) Implement respiratory hygiene and cough etiquette (i.e., placing a facemask over the patient's nose and mouth if that has not already been done)

(C) Have a separate, well-ventilated space that allows waiting symptomatic patients to be separated by 6 or more feet

(D) All of the above

Ans: (D)

(16) Clinical management includes prompt implementation of recommended infection prevention and control measures and supportive management of complications. No specific treatment for COVID-19 is currently available.

True or False

Ans : True

(17) A recommended infection prevention and control measure is to perform aerosol-generating procedures, including collection of diagnostic respiratory specimens, in an AllR (Airborne Infection Isolation Room).

True or False

Ans: True

FIGURE 9: Questionnaire page 4

Supplementary material: COVID-19 Awareness in Healthcare Professionals - Questionnaire

\section{Additional Information}

\section{Disclosures}

Human subjects: Consent was obtained by all participants in this study. IEC of Dr. D.Y. Patil School of Medicine, Navi Mumbai issued approval DYPH/IECBH/2020/01. Animal subjects: All authors have confirmed that this study did not involve animal subjects or tissue. Conflicts of interest: In compliance with the ICMJE uniform disclosure form, all authors declare the following: Payment/services info: All authors have declared that no financial support was received from any organization for the submitted work. Financial relationships: All authors have declared that they have no financial relationships at present or within the previous three years with any organizations that might have an interest in the submitted work. Other relationships: All authors have declared that there are no other relationships or activities that could appear to have influenced the submitted work.

\section{Acknowledgements}

Special thanks to Dr. Nimmy MR, Dr. Nanditha Reddy, Dr. Vinod Kammara, Dr. Vaishali and Dr. Devanshi for their help and support.

\section{References}

1. Cascella M, Rajnik M, Cuomo A, Dulebohn SC, Di Napoli R: Features, Evaluation and Treatment Coronavirus (COVID-19). StatPearls Publishing, Treasure Island, FL; 2020.

2. WHO Director-General's opening remarks at the media briefing on COVID-19-11 March 2020 . (2020). Accessed: Mar 19, 2020: https://www.who.int/dg/speeches/detail/who-director-general-s-opening-remarksat-the-media-briefing-on-covid-19---11-....

3. Langade D, Modi PD, Sidhwa YF, et al.: Burnout syndrome among medical practitioners across India: a questionnaire-based survey. Cureus. 2016, 8(9):e771. Accessed: March 3, 2020: 10.7759/cureus.771

4. Information for healthcare professionals. (2020). Accessed: March 19, 2020: https://www.cdc.gov/coronavirus/2019-ncov/hcp/index.html.

5. Hand hygiene: why, how \& when . (2020). Accessed: March 20, 2020: https://www.who.int/gpsc/5may/Hand_Hygiene_Why_How_and_When_Brochure.pdf.

6. India coronavirus cases: new cases take India coronavirus numbers to 415 , crucial info from ICMR likely 
tomorrow. (2020). Accessed: Mar 24, 2020: https://economictimes.indiatimes.com/news/politics-andnation/india-coronavirus-cases-touch-415-crucial-info-tommorro....

7. Modi PD, Kumar P, Solanki R, Modi J, Chandramani S, Gill N: Hand hygiene practices among Indian medical undergraduates: a questionnaire-based survey. Cureus. 2017, 9:e1463. Accessed: March 25, 2020: 10.7759/cureus. 1463

8. Frequently asked questions about hand hygiene for healthcare personnel responding to COVID-2019 . (2020). Accessed: March 20, 2020: https://www.cdc.gov/coronavirus/2019-ncov/infection-control/hcp-handhygiene-faq.html.

9. Interim infection prevention and control recommendations for patients with suspected or confirmed coronavirus disease 2019 (COVID-19) in healthcare settings. (2020). Accessed: March 20, 2020: https://www.cdc.gov/coronavirus/2019-ncov/infection-control/control-recommendations.html.

10. Sequence for putting on personal protective equipment (PPE) . (2020). Accessed: March 22, 2020: https://www.cdc.gov/hai/pdfs/ppe/ppe-sequence.pdf.

11. Feng S, Shen C, Xia N, Song N, Fan M, Cowling BJ: Rational use of face masks in the COVID-19 pandemic . Lancet Respir Med. 2020, S2213-2600(20):30134-X. Accessed: Mar 20, 2020: 10.1016/S2213-2600(20)30134$\mathrm{X}$

12. Asaad AM, El-Sokkary R, Mahdi A, Alzamanan, Shafei ME: Knowledge and attitudes towards Middle East respiratory syndrome-coronavirus (MERS-CoV) among health care workers in south-western Saudi Arabia. East Mediterr Health J. 2020, 25(x):xxx- xxx. Accessed: March 21, 2020: 10.26719/emhj.19.079

13. Alsahafi AJ, Cheng AC: Knowledge, attitudes and behaviours of healthcare workers in the Kingdom of Saudi Arabia to MERS coronavirus and other emerging infectious diseases. Int J Environ Res Public Health. 2016, 13:1214. 10.3390/ijerph13121214

14. A step India is taking could make doctor shortage a non-issue in coronavirus battle . (2020). Accessed: March 29, 2020: https://economictimes.indiatimes.com/industry/healthcare/biotech/healthcare/a-step-india-istaking-could-make-doctor-....

15. Mitjà O, Clotet B: Use of antiviral drugs to reduce COVID-19 transmission . Lancet Glob Health. 2020, 0:2214-109. Accessed: March 27, 2020: https://www.thelancet.com/journals/langlo/article/PIIS2214109X(20)30114-5/fulltext. 10.1016/S2214-109X(20)30114-5 